given the opportunity to work with senior leaders to develop their skills in leadership, strategy, project management and health policy. The fellows were exposed to the full spectrum of clinical senate work, clinical reviews, proactive projects, production and presentation of reports, as well as opportunities to attend meetings with senior leaders both locally and nationally.

Conclusions The clinical fellows enhanced the senate work programme by undertaking proactive projects. This allowed collaborative working with partner organisations, to evaluate models of care following service reorganisation, review the evidence regarding systems organisation and collaborative working for winter pressures and generate a narrative to bring physical activity as a treatment to the local healthcare agenda. Clinical fellowships offering the level of exposure to the rich opportunities for clinical leadership development that the East Midlands Clinical Senate has been able to offer are rare. Clinical senates provide innovative arenas for fellows to experience systems based thinking with tangible involvement as leadership figures and supporting leadership career development.

\section{LEADERSHIP CONVERSATIONS}

${ }^{1}$ Tim Swanwick, 'Louisa Hardman, ${ }^{2}$ Jo Szram. 'NHS Leadership Academy, 3 The Embankment, Sovereign Street, Leeds LS1 4BJ, UK; ${ }^{2}$ Health Education England, Stewart House, 32 Russell Square, London WC1B 5DN, UK

\subsection{6/leader-2019-FMLM.34}

The leadership of systems of care is increasingly recognised as a core clinical activity for all healthcare professionals. The GMC expects all postgraduate medical training programmes to equip trainees with leadership capabilities. But many supervisors feel ill equipped to 'teach' leadership and lack confidence to hold formative conversations in this domain. In 2017, HEE published a report on leadership development for doctors in postgraduate medical training identifying a need for 'faculty to think differently about their role and to be more confident in brokering leadership learning.' Three existing 'training the trainer' programmes were identified all with slightly differing approaches. Further needs analysis was conducted during 2018 through further focus groups of supervisors and trainees.

As a result of the above, a prototype training the trainers programme was designed alongside a comprehensive resource pack. This was piloted and then underwent 8 iterations. Each session was delivered by a member of NHS Leadership Academy faculty in partnership with a local clinician educator to a mixed audience of supervisors and senior educators. Following each session, resources were amended in the light of feedback. A final version was arrived at in May 19 with an emphasis on enhancing developmental interactions between trainees and trainers: 'Leadership Conversations'. The half day programme offers supervisors practice and structured guidance to enable them to integrate leadership learning into their regular discussions with trainees. It familiarises supervisors with a new resource pack, encouraging supervisors to use it for their own leadership learning as well as for trainees.

The sessions have evaluated well with feedback used to further modify the product. The programme - slide deck, trainers notes and resource pack - has since been disseminated for local delivery. Further evaluation and regular updates are planned including four accompanying short films due Oct 19.

\section{CATALYSING NURSE MIDDLE MANAGERS CLINICAL LEADERSHIP DEVELOPMENT THROUGH PEER-TO-PEER SHADOWING: START TOMORROW!}

${ }^{1}$ Pieterbas Lalleman*, ${ }^{2} J o a n n e$ Bouma, ${ }^{3}$ Gerhard Smid, ${ }^{4}$ Jananee Rasiah, ${ }^{5}$ Marieke Schuurmans. 'School of Nursing, University of Applied Sciences Utrecht, The Netherlands; ${ }^{2}$ Nij Smellinge Hospital, The Netherlands; ${ }^{3}$ Sioo, Interuniversity Centre for Organization Studies and Change Management, The Netherlands; ${ }^{4}$ Faculty of Nursing, University of Alberta, Canada; ${ }^{5}$ Utrecht University, The Netherlands

\subsection{6/leader-2019-FMLM.35}

Purpose The purpose of this study was to explore the experiences and impact of peer-to-peer shadowing as a technique to develop nurse middle managers' clinical leadership practices.

Design/Methodology/Approach A qualitative descriptive study was conducted to gain insight into the experiences of nurse middle managers using semi-structured interviews. Data were analysed into codes using constant comparison and similar codes were grouped under sub-themes and then into four broader themes.

Findings Peer-to-peer shadowing facilitates collective reflectionin-action and enhances an 'investigate stance' while acting. Nurse middle managers begin to curb the caring disposition that unreflectively urges them to act, to answer the call for help in the here and now, focus on ad hoc 'doings', and make quick judgements. Seeing a shadowee act produces, via a process of social comparison, a behavioural repertoire of postponing reactions and refraining from judging. Balancing the act of stepping in and doing something or just observing as well as giving or withholding feedback are important practices that are difficult to develop.

Originality/Value Peer-to-peer shadowing facilitates curbing the caring disposition, which is essential for clinical leadership development through unlocking a behavioural repertoire that is not easy to reveal because it is, unreflectively, closely knit to the professional background of the nurse managers. Unlike most leadership development programmes, that are quite introspective and detached from context, peer-to-peer shadowing does have the potential to promote collective learning while acting, which is an important process.

\section{Leading Innovation and Improvement}

\section{TOMORROW'S LEADERSHIP FOR EARLY-CAREER CLINICIANS: A MASTERCLASS MODEL}

Baguiasri Mandane*, Shiv Uppal, Raghad Elghadi. South East Midlands Oncology Centre, University Hospitals of Leicester NHS Trust. Leicester, UK

\subsection{6/leader-2019-FMLM.36}

Background The King's Fund report 'Leadership and engagement for improvement in the NHS: Together we can' describes the purpose of effective leadership, in a simplified manner, to improve population health and patient care. The aim of this project is to inspire and share ideas with other clinicians, on potential ways to build on our experiences from previous leadership models and how best to adjust going forward.

Method Following on from the literature review, we suggest incorporating mentoring-style leadership masterclasses for early-career clinicians as part of their continuous development from the very start of their training to help: 